\title{
Proof without words: Four circles
}

\author{
Ángel Plaza
}

In [1] is proved the following:

Theorem. Let $O, P$ and $Q$ be three points on a line, with $P$ lying between $O$ and $Q$. Semicircles are drawn on the same side of the line with diameters $O P$, $P Q$ and $O Q$. An arbelos is the figure bounded by these three semicircles. Draw the perpendicular to $O Q$ at $P$, meeting the largest semicircle at $S$. Then the area $C$ of the circle with diameter PS equals the area $A$ of the arbelos [Archimedes, Liber Assumptorum, Proposition 4].

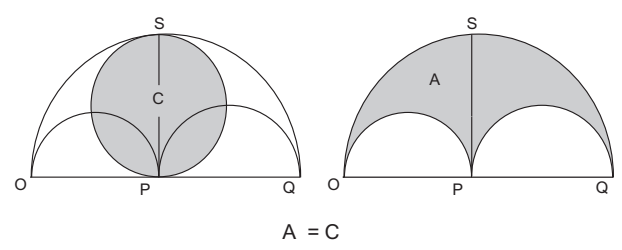

Here we prove without words the following:

Theorem. Let $O, P, Q$ and $R$ be four points on a line ordering from left to right. Semicircles are drawn on the same side of the line with with diameters $O Q, P R$, and semicircle with diameter $O R$ is drawn on the other side of the line. Draw the perpendiculars to $O R$ at $P$ and at $Q$ respectively, meeting the upper semicircles at $S$ and $T$, and the down semicircle at $S^{*}$ and $T^{*}$. Then the sum of the area of the circle with diameter $P S$ and the area of the circle with diameter 
$Q T^{*}$ equals the sum of the area of the circle with diameter $P S^{*}$ and the area of the circle with diameter $Q T$.

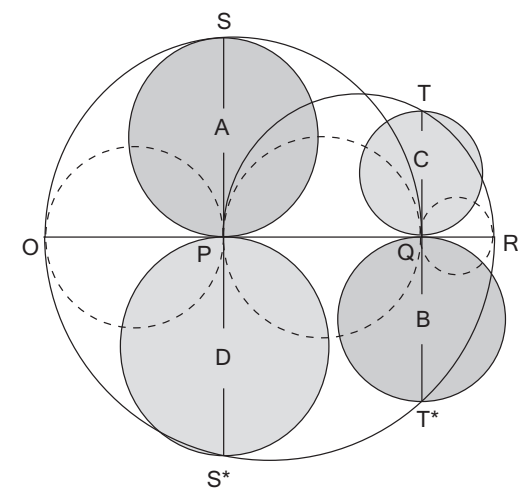

$A+B=C+D$

ProOF

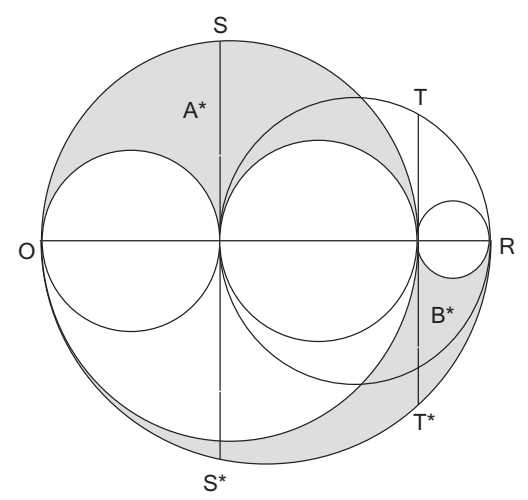

$A=A^{*} \& B=B^{*} \Longrightarrow A+B=A^{*}+B^{*}$

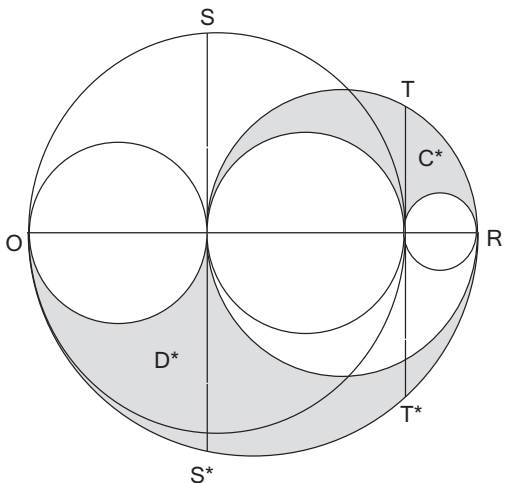

$C=C^{*} \& D=D^{*} \Longrightarrow C+D=C^{*}+D^{*}$

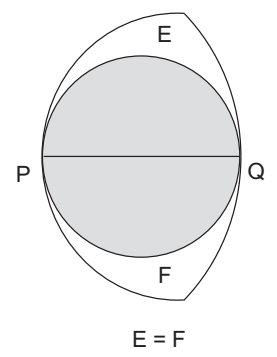



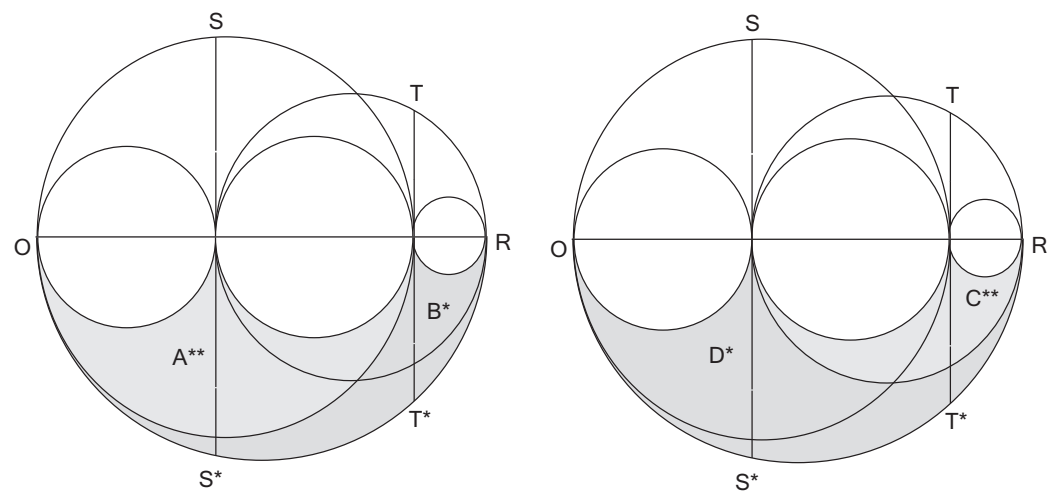

$$
\begin{gathered}
A^{*}=A^{* *} \& C^{*}=C^{* *} \\
\because \quad A+B=C+D
\end{gathered}
$$

\section{References}

[1] R. B. Nelsen, Proof without words: The area of an arbelos, Mathematics Magazine 75 (2002), 144.

ÁNGEL PLAZA

DEPARTMENT OF MATHEMATICS

UNIVERSITY OF LAS PALMAS DE GRAN CANARIA

EDIFICIO DE INFORMÁTICA Y MATEMÁTICAS

35017-LAS PALMAS DE GRAN CANARIA

SPAIN

E-mail: aplaza@dmat.ulpgc.es

(Received May, 2005) 